\title{
Structure of the ATP-Synthase from Chloroplasts and Mitochondria Studied by Electron Microscopy
}

\author{
Egbert J. Boekema
}

Fritz-Haber-Institut der Max-Planck-Gesellschaft, Faradayweg 4-6, D-1000 Berlin 33, Bundesrepublik Deutschland

Günter Schmidt, Peter Gräber

Max-Volmer-Institut, Technische Universität Berlin, Straße des 17. Juni 135, D-1000 Berlin 12, Bundesrepublik Deutschland

Jan A. Berden

Biochemisch Laboratorium, Universiteit van Amsterdam, Plantage Muidergracht 12, Amsterdam, The Netherlands

Z. Naturforsch. 43c, 219-225 (1988); received December 1, 1987

ATP-Synthase, Enzyme Structure, Electron Microscopy

The structure of the ATP-synthase, $\mathrm{F}_{0} \mathrm{~F}_{1}$, from spinach chloroplasts and beef heart mitochondria has been investigated by electron microscopy with negatively stained specimens. The detergent-solubilized ATP-synthase forms string-like structures in which the $F_{0}$ parts are aggregated. In most cases, the $F_{1}$ parts are arranged at alternating sides along the string. The $F_{0}$ part has an approximate cylindrical shape with heights of 8.3 and $8.9 \mathrm{~nm}$ and diameters of 6.2 and $6.4 \mathrm{~nm}$ for the chloroplast and mitochondrial enzyme, respectively.

The $F_{1}$ parts are disk-like structures with a diameter of about $11.5 \mathrm{~nm}$ and a height of about $8.5 \mathrm{~nm}$. The $F_{1}$ parts are attached to the strings, composed of $F_{0}$ parts, in most cases, with their smallest dimension parallel to the strings. The stalk connecting $F_{0}$ and $F_{1}$ has a length of $3.7 \mathrm{~nm}$ and $4.3 \mathrm{~nm}$ and a diameter of $2.7 \mathrm{~nm}$ and $4.3 \mathrm{~nm}$ for the chloroplast and mitochondrial enzyme, respectively.

\section{Introduction}

ATP synthesis/hydrolysis coupled with a transmembrane proton transport is catalyzed by a membrane-bound enzyme (ATP-synthase) in different types of organelles (chloroplasts, mitochondria, bacteria). It consists of a membrane-integrated part, $\mathrm{F}_{0}$, which is supposed to act as a proton channel through the membrane and a hydrophilic part, $\mathrm{F}_{1}$, which contains the nucleotide binding sites. The ATP-synthases from the different sources are very similar (for review see refs. [1-4]. The hydrophilic part of the ATP-synthase from chloroplasts $\left(\mathrm{CF}_{1}\right)$ and mitochondria $\left(\mathrm{MF}_{1}\right)$ is composed of five different subunits: $\alpha, \beta, \gamma, \delta$ and $\varepsilon[5,6]$. The stoichiometry of the $\mathrm{MF}_{1}$ subunits is $\alpha_{3} \beta_{3} \gamma \delta \varepsilon$ [6]; however, the number of copies of $\delta$ and $\varepsilon$ in $\mathrm{CF}_{1}$ is uncertain [4].

The hydrophobic part of the ATP-synthase from chloroplasts $\left(\mathrm{CF}_{0}\right)$ is composed of four different sub-

\footnotetext{
Abbreviations: $\mathrm{F}_{0} \mathrm{~F}_{1}$, proton translocating ATP-synthase; $\mathrm{F}_{0}$, membrane part of the ATP-synthase; $\mathrm{F}_{1}$, hydrophilic part of the ATP-synthase.

Reprint requests to Dr. E. J. Boekema.

Verlag der Zeitschrift für Naturforschung, D-7400 Tübingen 0341-0382/88/0003-0219 \$01.30/0
}

units I (18 kDa), II (16 kDa), III (8 kDa) and IV (25 kDa) [7-9]. The stoichiometry of the subunits is presumably $\mathrm{I}, \mathrm{II}_{2}, \mathrm{III}_{12}$, IV [10]. The hydrophobic $\mathrm{MF}_{0}$ part contains six subunits: $\mathrm{a}, \mathrm{b}, \mathrm{c}$ and $\mathrm{d}$ and $\mathrm{F}_{6}$ and $A_{6} L[11]$ and is less well understood because of its complexity.

Structural studies have mainly concentrated on isolated $\mathrm{F}_{1}$. X-ray diffraction has resulted in a lowresolution model showing six regions of approximately the same size [12]. On the basis of electron microscopy of single molecules and three-dimensional crystals, an arrangement of the larger subunits has been proposed [13-18]. The $F_{1}$ part is built up from two layers of the $\alpha$ - and $\beta$-subunits in the form of a flattened trigonal antiprism [14]. In the hexagonal projection, the small subunits $\gamma, \delta$ and $\varepsilon$ appear as a seventh mass in the center of the large subunits. This central mass is slightly displaced to one $\alpha-\beta$ pair (in $\mathrm{MF}_{1}$ ) [18].

Exact information on the shape and dimensions of the holoenzyme $F_{0} F_{1}$ is scarce. The $F_{1}$ part is connected by a stalk to the $F_{0}$ part [19-22]. Isolated $\mathrm{CF}_{0} \mathrm{CF}_{1}$ ATPase forms string-like aggregates in which the $\mathrm{CF}_{0}$ parts stick together $[20,21]$. In this work the ATP-synthetase from chloroplasts, $\mathrm{CF}_{0} \mathrm{~F}_{1}$, 
and mitochondria, $\mathrm{MF}_{0} \mathrm{~F}_{1}$, has been investigated by electron microscopy of negatively stained samples.

\section{Materials and Methods}

$\mathrm{CF}_{0} \mathrm{CF}_{1}$ ATPase was isolated from spinach chloroplasts according to $[23,10]$. It was finally dissolved in a concentration of $2-3 \mathrm{mg} / \mathrm{ml}$ in $30 \mathrm{~mm}$ Tris-succinate $\mathrm{pH} 6.5$ containing $2 \mathrm{mg} / \mathrm{ml}$ Triton $\mathrm{X}-100$, $0.2 \mathrm{~mm}$ ATP, $0.5 \mathrm{~mm}$ EDTA, $1 \mathrm{mg} / \mathrm{ml}$ asolectin and $900 \mathrm{~mm}$ sucrose. Reconstitution of $\mathrm{CF}_{0} \mathrm{CF}_{1}$ in asolectin liposomes was carried out as described in [24]. These preparations show rates of proton transportcoupled ATP synthesis practically identical with that observed in the natural membrane [24]. $\mathrm{MF}_{0} \mathrm{MF}_{1}$ was isolated according to [25] in a concentration of $33 \mathrm{mg} / \mathrm{min} 50 \mathrm{~mm}$ Tris- $\mathrm{HCl} \mathrm{pH}$ 7.5, $250 \mathrm{~mm}$ sucrose, $1 \mathrm{~mm}$ dithiotreitol and $0.2 \mathrm{~mm}$ EDTA.

Specimens were prepared by the droplet method or the Valentine method [26] using a 1\% uranyl acetate solution as negative stain. Electron microscopy was carried out on Philips EM 300 and EM 400 microscopes at 60-70,000 magnification. We used relatively small defocus values (mostly less than $200 \mathrm{~nm}$ ) which enhances the direct visualization of small details, since phase-contrast noise in the images is suppressed.

\section{Results}

Fig. 1 shows an SDS-gel of the $\mathrm{CF}_{0} \mathrm{~F}_{1}$ preparation used in this work. The preparation contains only the nine different subunits of $\mathrm{CF}_{0} \mathrm{~F}_{1}$, i.e., it is practically free of any impurity. An SDS-gel of a $\mathrm{MF}_{0} \mathrm{~F}_{1}$ preparation, similar in composition to the one used in this work, is shown in ref. [27].

Fig. 2 shows a part of an original micrograph of isolated $\mathrm{CF}_{0} \mathrm{~F}_{1}$. Single $\mathrm{CF}_{0} \mathrm{~F}_{1}$ molecules and different aggregates of $\mathrm{CF}_{0} \mathrm{~F}_{1}$ can be seen. Additionally, $\mathrm{CF}_{1}$ can be seen which is evidently disconnected from $\mathrm{CF}_{0}$. When $\mathrm{CF}_{0} \mathrm{~F}_{1}$ from this preparation is reconstituted into asolectin liposomes, half of the maximal rate of ATP synthesis $\left(200 \mathrm{~s}^{-1}\right)$ as in thylakoid membranes is observed [28]. We conclude from this result that the isolated $\mathrm{CF}_{0} \mathrm{~F}_{1}$ is essentially intact and that the disconnection of $\mathrm{CF}_{1}$ from $\mathrm{CF}_{0}$ occurs during the dilution and staining procedure for electron microscopy. The best specimens for electron microscopy were obtained by diluting the sample about 30 times with $10 \mathrm{~mm}$ Tris- $\mathrm{HC}_{1} \mathrm{pH}$ 7.5. Electron micrographs

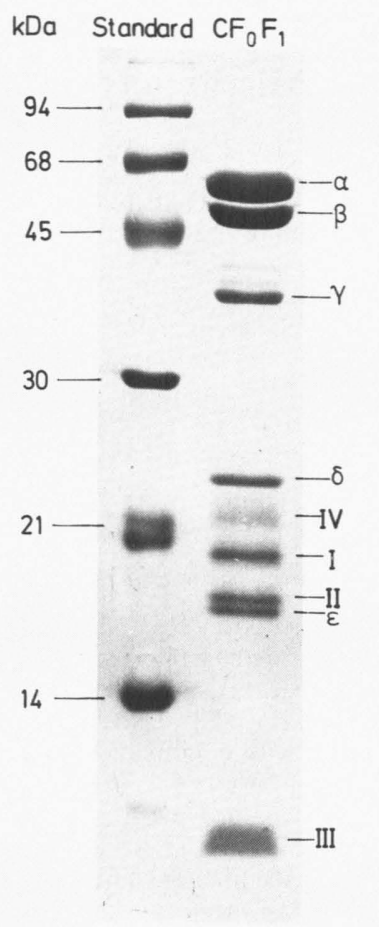

Fig. 1. SDS-gel of $\mathrm{CF}_{0} \mathrm{~F}_{1}$; left lane protein standards, right lane $\mathrm{CF}_{0} \mathrm{~F}_{1} \cdot \mathrm{CF}_{0} \mathrm{~F}_{1}$ was incubated in a buffer containing $62.5 \mathrm{~mm}$ Tris- $\mathrm{Cl} \mathrm{pH}=7.5,2 \%(\mathrm{w} / \mathrm{v}) \mathrm{SDS}, 5 \%(\mathrm{v} / \mathrm{v})$ glycerol and $10 \%$ mercaptoethanol for $5 \mathrm{~min}$ at $95^{\circ} \mathrm{C}$. Then $25 \mu \mathrm{g}$ of the preincubated $\mathrm{CF}_{0} \mathrm{~F}_{1}$ was used for gel electrophoresis. Stacking gel contains $3.75 \%$ acrylamide, the separation gel $15 \%$.

from $\mathrm{MF}_{0} \mathrm{~F}_{1}$ show similar results. In this case optimal results were obtained by diluting the sample about 250 times with $10 \mathrm{~mm}$ Tris- $\mathrm{HC}_{1} \mathrm{pH} \mathrm{7.5,} \mathrm{containing}$ $0.15 \%$ octylglucoside. Omission of the detergent results in big aggregates of randomly clustered protein material.

Fig. $3 \mathrm{~A}$ shows a gallery of $\mathrm{F}_{0} \mathrm{~F}_{1}$ strings. The upper three rows show $\mathrm{CF}_{0} \mathrm{~F}_{1}$, the lower two $\mathrm{MF}_{0} \mathrm{~F}_{1}$. Fig. 3B shows some single molecules and strings with our schematic interpretation on the left side of the corresponding electron micrograph(s). The $F_{0}$ part (dashed area) is strongly hydrophobic and therefore has the tendency to aggregate. The $F_{0}$ part is smaller than the $F_{1}$ part. This has consequences for the preparation of the strings for electron microscopy. Upon drying, the $F_{1}$ parts will become attached to the carbon support film. Since they are so big, their position will mostly alternate on the strings, avoiding overlap or friction. It can be seen from Fig. 3 that on most 


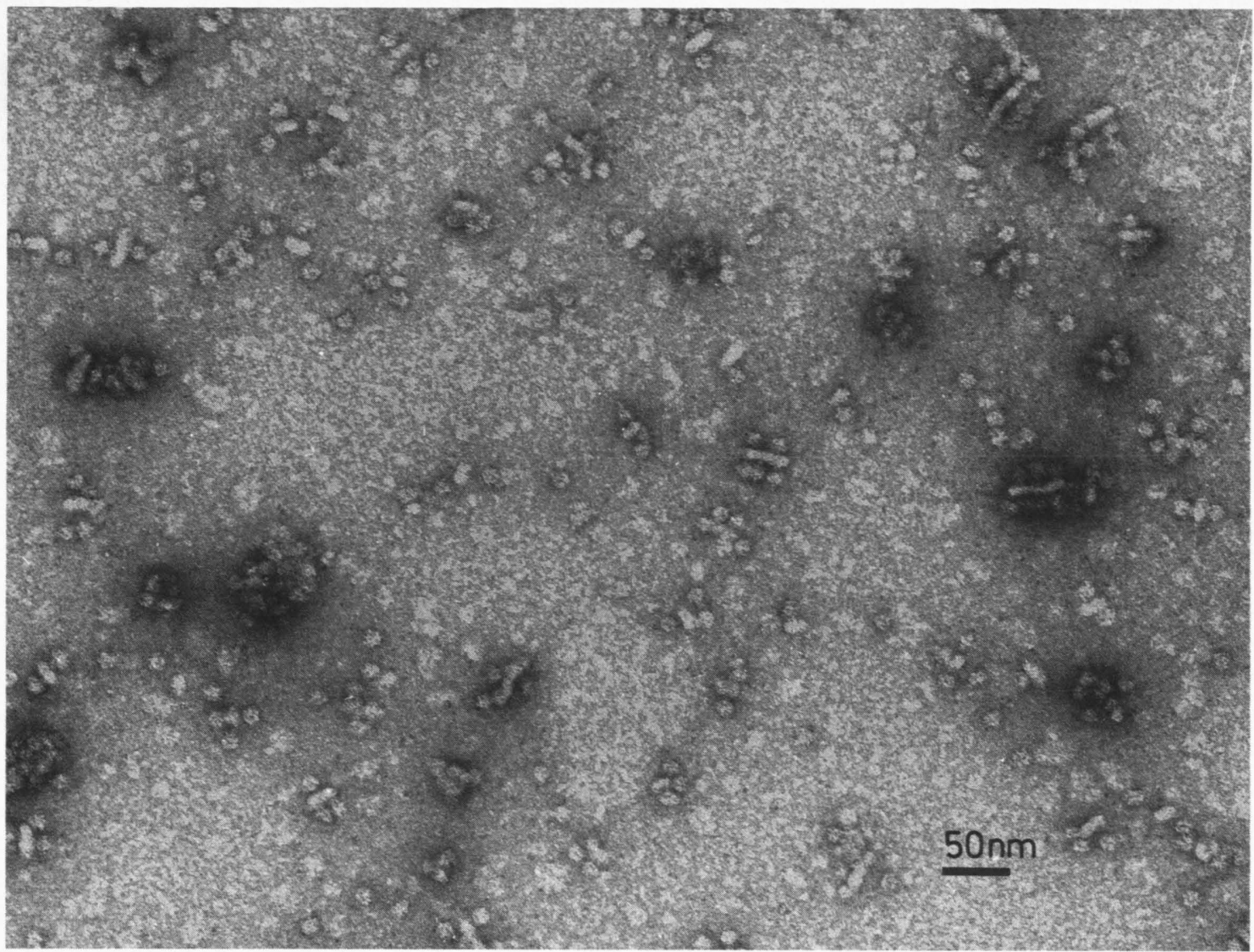

Fig. 2. Part of an original electron micrograph showing $\mathrm{CF}_{0} \mathrm{~F}_{1}$. The specimen was stained negative with $1 \%$ uranyl acetate. The electron optical magnification was 70,000 .

strings adjacent $\mathrm{F}_{1}$-parts are alternating and not neighboring.

The contours of the $F_{1}$ parts on the strings can be seen clearly. In some cases, the length of $F_{1}$ parallel to the string was considerably longer than that vertical to the string (e.g., Fig. $3 \mathrm{~A}$, the first micrographs in rows $1-3)$. In other cases, the dimensions parallel and vertical to the string were quite similar (see e.g. micrograph 7 , row 1$)$. On the average, for $\mathrm{CF}_{1}$ $11 \mathrm{~nm}$ resulted parallel to the string and $8.3 \mathrm{~nm}$ vertical to the string; for $\mathrm{MF}_{1} 11.7 \mathrm{~nm}$ and $9.0 \mathrm{~nm}$, resp., resulted (see Table I).

The $F_{1}$ parts are connected to the strings by a stalk. For $\mathrm{CF}_{1}$ the length of the stalk is $3.7 \mathrm{~nm}$, its diameter $2.7 \mathrm{~nm}$ (see Table I). If $\mathrm{CF}_{0} \mathrm{CF}_{1}$ is reconstituted into asolectin liposomes, the length of the stalk is found to be $3.2 \pm 0.8 \mathrm{~nm}$ (number of measurements: 24 ). The diameter of the stalk could not be measured with accuracy in the reconstituted system. For $\mathrm{MF}_{1}$ the length of the stalk is $4.3 \mathrm{~nm}$, its diameter is also $4.3 \mathrm{~nm}$ (see Table I).

The thickness of the strings can be easily measured. Values of 8.3 and $8.9 \mathrm{~nm}$ were found for $\mathrm{CF}_{0}$ and $\mathrm{MF}_{0}$, respectively (Table I). A phospholipid

Table I. Dimensions of the isolated $\mathrm{CF}_{0} \mathrm{~F}_{1}$ and $\mathrm{MF}_{0} \mathrm{~F}_{1}$. The measured parameters are defined in Fig. 5. Additionally, the standard deviation and number of measurements (in brackets) are given.

\begin{tabular}{crr}
\hline Length [nm] & \multicolumn{1}{c}{$\mathrm{MF}_{0} \mathrm{~F}_{1}$} & \multicolumn{1}{c}{$\mathrm{CF}_{0} \mathrm{~F}_{1}$} \\
\hline $\mathrm{a}$ & $11.7 \pm 0.9(50)$ & $11.0 \pm 1.1(36)$ \\
$\mathrm{b}$ & $9.0 \pm 0.8(50)$ & $8.3 \pm 1.0(36)$ \\
$\mathrm{c}$ & $4.3 \pm 1.0(42)$ & $2.7 \pm 0.6(36)$ \\
$\mathrm{d}$ & $4.3 \pm 0.6(42)$ & $3.7 \pm 0.7(36)$ \\
$\mathrm{e}$ & $8.9 \pm 0.8(68)$ & $8.3 \pm 0.8(83)$ \\
f & $6.4 \pm 0.7(72)$ & $6.2 \pm 0.4(24)$ \\
\hline
\end{tabular}


A
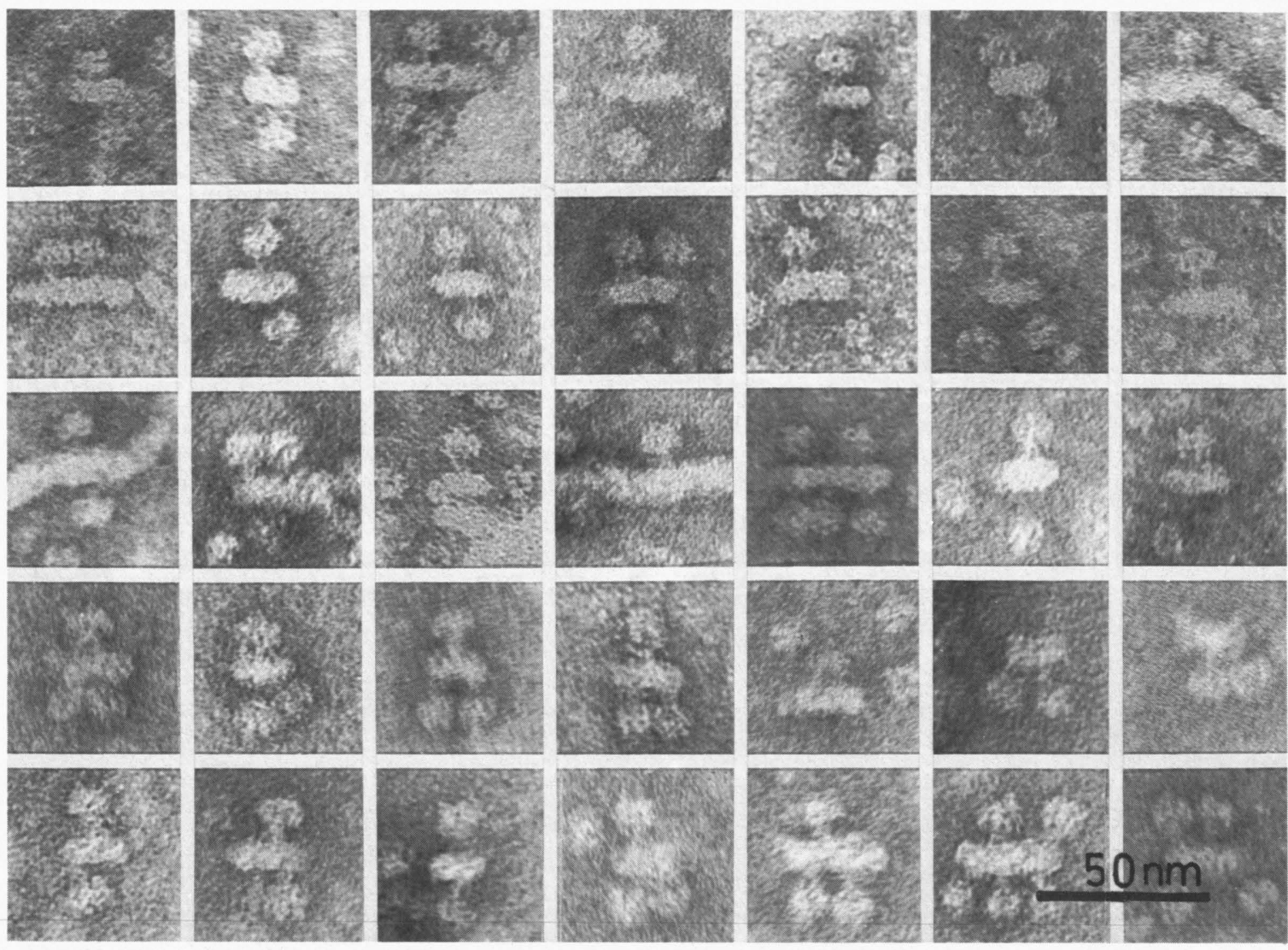

B
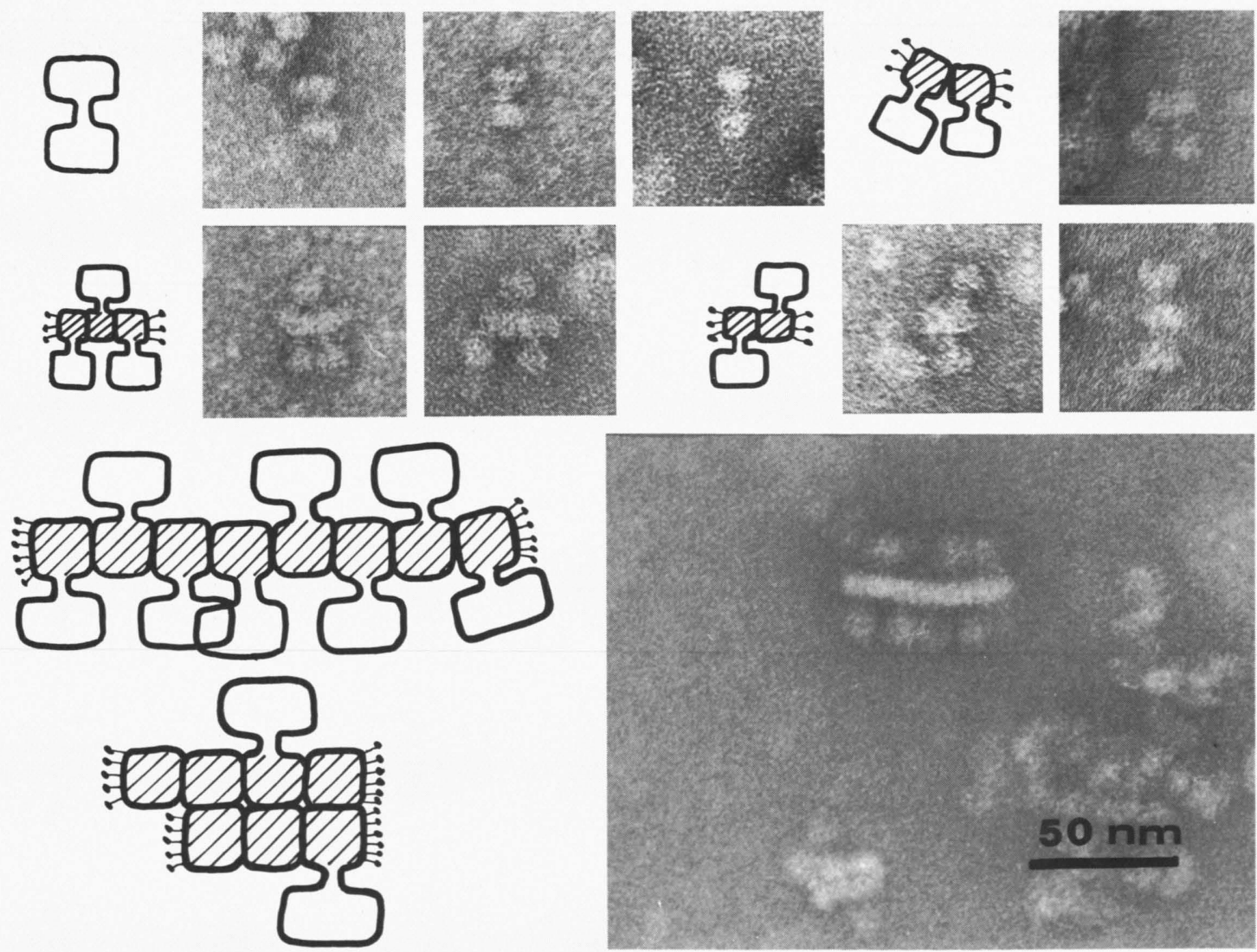

Bereitgestellt von | Technische Universität Berlin 
bilayer has a thickness of about $5 \mathrm{~nm}$ [29], and, in principle, even thinner proteins can span the lipid membrane, like bacteriorhodopsin which has a thickness of about $4 \mathrm{~nm}$ [30]. In theory, it could be that the strings are built from a double row of $F_{0}$ parts having a thickness of about $4.3 \mathrm{~nm}$. But this is unlikely since in no case single strings of that size were observed. Moreover, single $\mathrm{MF}_{0} \mathrm{~F}_{1}$ molecules never show such a small dimension. Therefore we conclude that the strings must be formed from rows of $F_{0}$ parts having a thickness of about $8 \mathrm{~nm}$. The interpretation is illustrated by examples in Fig. 3B.

The dimensions of the $\mathrm{F}_{0}$ parts parallel to the strings are difficult to measure directly from single units since these parts usually stick together forming smaller or longer beads, their length depending on the detergent concentration. By measuring the full length of well preserved strings and by counting the number of attached $F_{1}$ parts on both sides, there is a way to estimate the length of $\mathrm{F}_{0}$ along the strings. We assume that the $F_{0}$ parts do not overlap significantly, since the strings are evenly stained. We measured 126 of these strings being composed of $2-11 \mathrm{~F}_{0} \mathrm{~F}_{1}$ complexes. Fig. 4 shows the length of the string as a function of the number of $F_{1}$ parts. The slope of this curve is the increase in length of the string per $F_{1}$. A length of 6.2 and $6.4 \mathrm{~nm}$ resulted for $\mathrm{CF}_{1}$ and $\mathrm{MF}_{1}$, respectively (Fig. 4 and Table I).

In our interpretation this length is the smallest dimension of the $\mathrm{F}_{0}$ part along the string. The straight curves in Fig. 4A and 4B imply that all strings are packed in a similar way. It is noteworthy that the curves, if extrapolated, are not going through the origin. They extrapolate to $3.6 \mathrm{~nm}$ and this length can be interpreted as the length of the detergent which must be present at both ends of the string. The length of the detergent octylglucoside is $1.8 \mathrm{~nm}$, which is in surprisingly good agreement with the extrapolated value.

\section{Discussion}

These results and considerations lead to a model of the $\mathrm{F}_{0} \mathrm{~F}_{1}$ ATP-synthase shown in Fig. 5. The hydrophilic $F_{1}$ part is connected by a stalk to the $F_{0}$ part, the $F_{0}$ part is embedded in the membrane and the
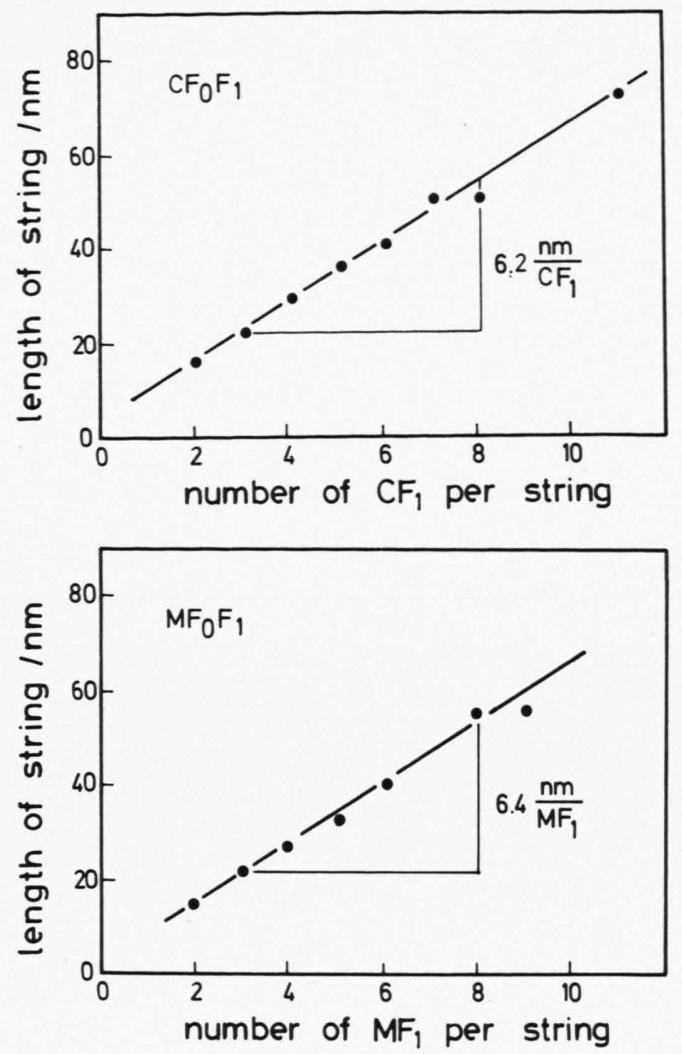

Fig. 4. String length as a function of the number of attached $F_{1}$-parts. The slope gives the string length per $F_{1}$, i.e., the maximal dimensions of $\mathrm{F}_{0}$ in the direction of the string. Top: $\mathrm{CF}_{0} \mathrm{~F}_{1}$; bottom: $\mathrm{MF}_{0} \mathrm{~F}_{1}$.

thickness of the membrane is smaller than the length of $\mathrm{F}_{0}$. Additionally, in Fig. 5 the dimensions are difined which are listed in Table I. The dimensions of the $F_{1}$ part found in our work are, within error limits, in accordance with the data from $\mathrm{X}$-ray diffraction where dimensions of $12 \times 11 \times 8 \mathrm{~nm}$ have been found [12] and also with earlier electron microscopy data [13-17]. The dimensions of the stalk reported here are also in accordance with earlier electronmicroscopic work: for $\mathrm{MF}_{0} \mathrm{~F}_{1}$ a stalk of $4.0 \times 3 \mathrm{~nm}$ has been reported [31], for $E$. coli $\mathrm{F}_{0} \mathrm{~F}_{1}, \mathrm{EF}_{0} \mathrm{~F}_{1}$, a stalk of $4.5 \times 2 \mathrm{~nm}$ was found [32], and for $\mathrm{CF}_{0} \mathrm{~F}_{1}$ the distance of the $\mathrm{CF}_{1}$ part from the membrane has been estimated from fluorescence energy transfer data to be

Fig. 3. A: A gallery of isolated ATP-synthases. Upper three rows show $\mathrm{CF}_{0} \mathrm{~F}_{1}$, the lower two rows show $\mathrm{MF}_{0} \mathrm{~F}_{1}$. Total magnification is 420,000 .

B: Selected parts of micrographs illustrating the packing of isolated $F_{0} F_{1}$ molecules. On the left side of each micrograph our interpretation of the observed structure is given. The dashed area shows the aggregated $\mathrm{F}_{0}$ parts. 


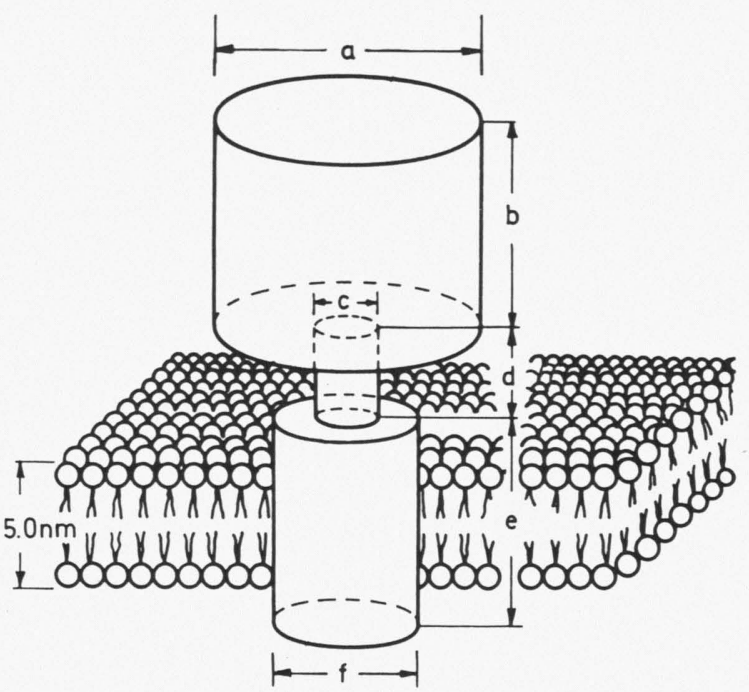

Fig. 5. A model for the shape of the ATP-synthase in a lipid bilayer. The different measured parameters are defined in this figure. The corresponding numbers are given in Table I. The figure is drawn in scale for $\mathrm{CF}_{0} \mathrm{~F}_{1}$.

between 3-4.5 $\mathrm{nm}$ [33]. However, the stalk dimensions of several systems do not need to be the same since the number of subunits differs. The ATP-synthase from E. coli has the smallest stalk [32], and is the simplest system with only 8 subunits, whereas $\mathrm{MF}_{0} \mathrm{~F}_{1}$ has 5 subunits more, located in the stalk and $\mathrm{F}_{0}$ part [11]. For the $\mathrm{F}_{0}$ part, a thickness of the string of $8.3 \mathrm{~nm}$ (or $8.9 \mathrm{~nm}$ ) was found and we assume that this represents the length of $\mathrm{F}_{0}$ through the membrane. The length of the $F_{0}$ part is surprisingly long. Since a phospholipid bilayer has a thickness of only $5 \mathrm{~nm}$ [29], this means that a large part of $\mathrm{F}_{0}$ is outside the membrane.

The length of the string per $F_{1}$ is $6.2 \mathrm{~nm}$ (or $6.4 \mathrm{~nm}$ ) and in our interpretation this represents the diameter of the $\mathrm{F}_{0}$ part, in case the $\mathrm{F}_{0}$ part has a circular shape. The length of $6.2 \mathrm{~nm}$ has to be considered as the maximal value: if there were detergent molecules located between neighboring $\mathrm{F}_{0}$ parts, this would be included in this type of measurement and the $F_{0}$ part alone would be smaller. It is not clear from our results whether the $F_{0}$ part has indeed a circular shape, e.g. an ellipsoid shape could also be realized. In the latter case, one has to assume that along the string axis the smaller dimension is found and that the dimension perpendicular to the string axis should be bigger since this would result in a bigger area of contact between the hydrophobic $\mathrm{F}_{0}$ parts with a corresponding lowering of the free energy of the system. However, presently there is no evidence for this, and for the sake of simplicity we assume a circular shape of the $F_{0}$ part.

Micrographs of single ATP-synthase molecules, purified from rat liver mitochondria with deoxycholate have been presented [19]. From these images it was concluded that $\mathrm{F}_{0}$ has a diameter of $10-12 \mathrm{~nm}$. Since it is impossible that such $\mathrm{F}_{0} \mathrm{~F}_{1}$ particles remain monodispersed without attached detergents, the real diameter is much smaller. According to Fig. 4 the (extrapolated) diameter for one $F_{0}$ is about $10 \mathrm{~nm}$, however, $3.6 \mathrm{~nm}$ are due to the detergent. Electron micrographs from reconstituted $\mathrm{CF}_{0} \mathrm{~F}_{1}$ obtained with the freeze-fracture technique have shown particles with a diameter of $8.3 \mathrm{~nm}[21,34]$. If the size overestimation due to the platinum replication technique is corrected, a diameter of about $6 \mathrm{~nm}$ can be estimated; in good agreement with our results.

However, the arrangement of the $F_{1}$ part relative to the $F_{0}$ part is controversial. Our data indicate that in most cases the longer dimension of $F_{1}$ is parallel to the string axis and, therefore, we assume that it is also parallel to the membrane surface. Electron micrographs from reconstituted $\mathrm{EF}_{0} \mathrm{~F}_{1}$ and $\mathrm{MF}_{0} \mathrm{~F}_{1}$ indicate that the longer dimension is vertical to the membrane surface [31, 32]. It is not yet clear whether this difference reflects actual differences (isolated versus reconstituted) or whether it represents an artifact of the specimen preparation, i.e., upon staining and drying on the carbon film the position of the $F_{1}$ parts relative to the $F_{0}$ parts is changed. Single $M_{1}$ and $\mathrm{CF}_{1}$ molecules, if prepared under the same conditions as the $\mathrm{MF}_{0} \mathrm{~F}_{1}$ and $\mathrm{CF}_{0} \mathrm{~F}_{1}$ molecules, will seldom lay on their side (less than $1 \%$ out of 4000 molecules ([18] and unpublished), since the molecules have a strong tendency to stick with their hexagonal (top) side to the carbon support. Despite the fact that the side view position for $F_{1}$ molecules is apparently very unfavourable, we still find most $\mathrm{F}_{0} \mathrm{~F}_{1}$ molecules arranged in this position.

\section{Acknowledgements}

We thank Prof. B. Rumberg for stimulating this work, Prof. E. Zeitler for continuous support, P. Fromme for the SDS-gel of $\mathrm{CF}_{0} \mathrm{~F}_{1}$ and Matina Gerdsmeyer for excellent technical assistance. This work was supported by the Deutsche Forschungsgemeinschaft (Sfb 312). 
[1] L. M. Amzel and P. L. Pedersen, Ann. Rev. Biochem. 52, 801 (1983).

[2] A. E. Senior and J. G. Wise, J. Membr. Biol. 73, 105 (1983).

[3] H. Strotmann and S. Bickel-Sandkötter, Annu. Rev. Plant Physiol. 35, 97 (1984).

[4] R. E. McCarty and C. M. Nalin, in: Photosynthesis III (Staehelin, L. A. and Arntzen, C. J., eds.), Springer Verlag, Berlin 1986.

[5] N. Nelson, D. W. Deters, H. Nelson, and E. Racker, J. Biol. Chem. 248, 2049 (1973).

[6] J. E. Walker, I. M. Fearnly, N. J. Gay, B. W. Gibson, F. D. Northrop, S. J. Powell, M. J. Runswick, M. Saraste, and V. L. J. Tybulewicz, J. Mol. Biol. 184, 677 (1985).

[7] P. Fromme, P. Gräber, and J. Salnikow, FEBS Lett. 218, 27 (1987).

[8] U. Pick and E. Racker, J. Biol. Chem. 254, 2793 (1979).

[9] K. H. Süß and O. Schmidt, FEBS Lett. 144, 213 (1982).

[10] P. Fromme, E. J. Boekema, and P. Gräber, Z. Naturforsch. 42 c, 1239 (1987).

[11] J. E. Walker, M. J. Runswick, and L. Poulter, J. Mol. Biol. 197, 89 (1987).

[12] L. M. Amzel, M. McKinney, P. Narayanan, and P. L. Pedersen, Proc. Natl. Acad. Sci. 79, 5852 (1982).

[13] H. Tiedge, G. Schäfer, and F. Mayer, Eur. J. Biochem. 132, 37 (1983).

[14] V. L. Tsuprun, I. V. Mesyanzhinova, I. A. Kozlov, and E. V. Orlova, FEBS Lett. 167, 285 (1984).

[15] C. W. Akey, V. Spitsberg, and S. J. Edelstein, J. Biol. Chem. 258, 3222 (1983).

[16] H. Tiedge, H. Lünsdorf, G. Schäfer, and H. U. Schairer, Proc. Natl. Acad. Sci. U.S.A. 82, 7874 (1985).
[17] H. Lünsdorf, K. Ehrig, P. Friedl, and H. U. Schairer, J. Mol. Biol. 173, 131 (1985).

[18] E. J. Boekema, J. A. Berden, and M. G. van Heel, Biochim. Biophys. Acta 851, 353 (1986).

[19] J. W. Soper, G. L. Decker, and P. L. Pedersen, J. Biol. Chem. 254, 11170 (1979).

[20] Y. Kagawa, Biochim. Biophys. Acta 265, 297 (1972).

[21] J. E. Mullet, U. Pick, and C. J. Arntzen, Biochim. Biophys. Acta 642, 149 (1981).

[22] E. Mörschel and L. A. Staehlin, J. Cell Biol. 97, 301 (1983).

[23] U. Pick and E. Racker, J. Biol. Chem. 254, 2793 (1979).

[24] G. Schmidt and P. Gräber, Biochim. Biophys. Acta 808, 46 (1985).

[25] J. A. Berden and M. M. Voorn-Brouwer, Biochim. Biophys. Acta 501, 424 (1978).

[26] R. C. Valentine, B. M. Shapiro, and E. R. Stadmann, Biochemistry 7, 2143 (1968).

[27] J. A. Berden and M. A. C. Henneke, FEBS Lett. 126, 211 (1981).

[28] G. Schmidt and P. Gräber, Biochim. Biophys. Acta 890, 392 (1987).

[29] J. Stamatoff, T. Bilash, Y. Ching, and P. Eisenberger, Biophys. J. 28, 413 (1979).

[30] R. Henderson and P. N. T. Unwin, Nature 257, 28 (1975).

[31] V. L. Tsuprun, I. V. Mesyanzhinova, Y. M. Milgrom, and T. Yu. Kalashnikova, Biochim. Biophys. Acta 892, 130 (1987).

[32] E. P. Gogol, U. Lücken, and R. A. Capaldi, FEBS Lett. 219, 274 (1987).

[33] R. E. McCarty and G. G. Hammes, TIBS 12, 234 (1987).

[34] J. L. Rigaud, T. Gulik-Krzywicki, and M. Seigneuret, J. Biol. Chem., in press. 